\title{
La destrucción del orbe patriarcal en El color del verano de Reinaldo Arenas
}

\author{
Francisco Ramón Castro Hernández ${ }^{1}$ y Gabriel Osuna Osuna ${ }^{2}$
}

Resumen. El presente artículo explora y analiza las relaciones existentes entre la voz narrativa del protagonista y los diferentes niveles de enunciación que se establecen con el mundo construido en El color del verano (1991) de Reinaldo Arenas. Se ha utilizado la teoría de género, además de algunos conceptos derivados de las propuestas teóricas de Mijaíl Bajtín para determinar cómo el universo creado en la novela establece relaciones particulares reveladoras. El mundo posible construido artificialmente a través del texto artístico demuestra una agenda política relacionada con una estética de lo grotesco y una hiperbolización de la realidad que corresponde con las tendencias estéticas latinoamericanas del momento histórico en el que se escribe el texto.

Palabras clave: Reinaldo Arenas; género; sujeto; marginalidad; homosexualidad y literatura; desestabilización.

\section{[en] The destruction of the patriarchal world in Reinaldo Arenas' El color del verano}

\begin{abstract}
This article explores and analyzes some relations between the narrative voice of the main character and the different levels of enunciation presented in Reinaldo Arenas' El color del verano (1991). We have used both the gender theory and theoretical concepts from Mikhail Bakhtin to determine how the universe created in the novel establish particular relations with the world. The possible world artificially constructed through the artistic text demonstrates a political agenda related with the aesthetic of the grotesque. It creates a clear hiperbolization of the reality connected with Latin American aesthetic trends within the historical moments in which the novel was created.
\end{abstract}

Keywords: Reinaldo Arenas; gender; subject; marginality; homosexuality and literature; destabilization.

Sumario: 1. Introducción teórico-crítica. 2. Sobre la institución de un sujeto marginal homosexual. 3. La ordenación simbólica desde su formulación falogocéntrica. 4. La desestabilización como propuesta para un nuevo valor simbólico.

Cómo citar: Castro Hernández, F.R. y Osuna Osuna, G. (2021) La destrucción del orbe patriarcal en El color del verano de Reinaldo Arenas, en Anales de Literatua Hispanoamericana 50, 341-352.

\section{Introducción teórico-crítica}

El objetivo de este artículo es determinar los alcances de la problemática de género que presenta El color del verano (1991) de Reinaldo Arenas (1943-1990), y su relación con la estética de lo grotesco, que le permite operar como texto artístico dentro de la tradición latinoamericana de fin de siglo ${ }^{3}$. El presente ensayo sostiene que 1) la configuración del orbe se da desde la enunciación subversiva de las marcas de género a partir del lenguaje mismo, en un acto tan sencillo y queer como la feminización de los personajes; 2), esta feminización se contrapone al orbe patriarcal que impera casi de manera tácita pero detectable; y, finalmente, 3) que de lo anterior se sigue un enfrentamiento y posterior subversión de las estructuras que, de acuerdo con el contexto, resulta inusitado para la literatura hispanoamericana y caribeña contemporáneas al autor.

\footnotetext{
1 Universidad de Sonora. México.

E-mail: frcastroh@gmail.com

${ }^{2}$ Universidad de Sonora. México.

E-mail: gabriel.osuna@unison.mx

${ }^{3}$ El presente trabajo parte de una investigación más amplia, cuya tesis propone por un lado el análisis de esta novela desde la perspectiva de género y, por otro, desde la tradición estética del carnaval y lo grotesco señaladas por Mijaíl Bajtín en La cultura popular en la Edad Media y en el Renacimiento: el contexto de François Rabelais (1941).
} 
Algunas cuestiones de género, en tanto construcción de la identidad, permiten establecer posibles pautas de lectura. Al dejar de lado la cuestión estética referida a lo cómico y el carnaval, se muestra posible determinar la función que despliegan los mecanismos de lo camp o queer en el texto, para generar la percepción de representatividad política en el lector. En un artículo sobre El color del verano (en adelante $E C V)$, Rosa María Díez Cobo apunta que esta novela es la historia que "mejor representa su proyecto creativo [el de Arenas] de cinco narrativas conocido como la Pentagonía" (2007). Por otra parte, Daniel Nemrava propone que "la novela de Arenas tiene un infernal carácter laberíntico que evoca la decadente Habana" (2014: 48) al comparar ECV con la narrativa de Kafka. No obstante, parte de la crítica centra su atención en las dificultades o fallas de esta obra póstuma del autor cubano. Por ejemplo, José Miguel Oviedo menciona que la novela en cuestión "es un panfleto anticastrista casi del todo carente de interés literario" (2001: 365); también, sobre otros asuntos, Correa Mujica menciona que "Arenas tenía un concepto heterosexual e inmaduro sobre la homosexualidad" (1999) ${ }^{4}$.

De lo anterior se desprende la propuesta de la revisión del texto desde una perspectiva de género que también considere el contexto hispanoamericano. Es importante tomar en cuenta que aquello que hoy se identifica con los estudios queer tiene sus precedentes en la época en que Arenas terminaba su obra. De aquella etapa finisecular provienen las contribuciones de Judith Butler por alcanzar una revisión afortunada acerca de las concepciones culturales de la problemática de género, a través de planteamientos de teóricos como Monique Wittig y Michel Foucault; mientras que Joan Wallach Scott hacía hincapié en la necesidad de diseñar una teoría que permitiera alcanzar una adecuada representatividad discursiva. En este sentido, la posición central del lenguaje es esencial, ya que las categorías lingüísticas para nombrar la disidencia se vuelven políticas y se convierten en herramientas para cuestionar la heteronormatividad desde su proyecto cultural.

Trasladar la teoría al contexto hispanoamericano, por otra parte, implica también una revisión de los presupuestos culturales de la región. Si bien estos no son del todo ajenos a las propuestas teóricas anglosajonas, sí contienen sus propios matices en lo correspondiente al nombramiento de las categorías disidentes. Los estudios de Guillermo Núñez Noriega en México contribuyen en la comprensión de la categoría "hombre" sin la exclusividad otorgada por el pensamiento occidental heteronormativo. Este autor reconoce una aculturación ideológica tanto en los términos como en las formas de concebir la sexualidad, generados desde los intereses históricos y políticos de determinados grupos precisamente a finales del siglo $\mathrm{XX}$ :

El término gay surge en Estados Unidos como categoría de identidad política para contestar al discurso médico y policiaco de la homosexualidad y para reivindicar una actitud vital y positiva hacia la sexualidad (gay significa alegre) frente a los valores estoicos y mortificantes del ideal sexual y, en general, de la sensibilidad ideal del patriarcado, más común tal vez en los años sesenta y setenta, cuando el término gay adquirió su uso claramente político. En México, el término fue retomado por varones urbanos de clase media (aunque también por mujeres) para evitar el estigma de las expresiones populares homofóbicas y del vocablo homosexual por su carga médica (Núñez: 2016, 41).

Previamente, Núñez reconoce el uso de las representaciones sociales para instituir lo simbólico desde lo que llama "trilogía de prestigio", compuesta por los términos "hombre-masculinidad-heterosexualidad" donde estos conceptos "a nivel de sentido común se implican [...] de tal suerte que cualquiera de ellos puede llegar a resumir los otros dos" (2015: 61). Así, en el complejo campo de relaciones sexuales, y en el contexto específico en el que desarrolla su estudio (la región fronteriza de Sonora, en el norte de México), Núñez observa un consenso en cuanto a las categorías para indicar la amplitud del espectro en lo concerniente a las prácticas sexuales gracias, además de lo anterior, a la "gran permisibilidad que existe para los individuos que juegan el papel «activo» en relaciones anales o en el de sexo oral (el de penetrador)" (Núñez, 2015: 220). En lo referente a las relaciones sexuales entre varones, la categoría "mayate" sustituye al agente activo: "«el mayate» no se considera y no es considerado «homosexual», se le considera a veces como «un vividor», pues intercambia favores sexuales o compañía por dinero, cerveza, etcétera; «el jalador» establece contacto

\footnotetext{
${ }^{4}$ Aunque la crítica se hace en torno a su autobiografía, se han establecido lazos que relacionan a Antes que anochezca con El color el verano, al ser estas sus dos últimas obras. Para Christopher Winks, por ejemplo, ECV se presenta como el "doble carnavalesco" de Antes que anochezca, pues "muchos de los incidentes relatados en la autobiografía reaparecen en la novela, grotescamente transformadas en «literatura»" (2008: 104).
} 
erótico por placer" (2015: 223). Aunque la cita mencione al "jalador", este vocablo en México no tiene un uso tan extendido como el anterior. A estos conceptos se contraponen términos como "joto" o "marica" para referirse al homosexual propiamente afeminado, como categoría necesaria para complementar incluso la categoría hegemónica tripartita mencionada arriba. Esta otra estructura para designar la otredad, según Núñez, está conformada por "naturaleza rara-homosexual-feminidad" (2015: 304).

En este punto, la dupla integrada por los "pájaros" o "locas" frente a los personajes masculinos identificados propiamente como "hombres" o "bugarrones" en ECV puede homologarse a la estudiada por Núñez en Sexo entre varones, en donde la identidad homosexual del afeminado (el término "loca" es también muy extendido en el territorio mexicano) corresponde al joto mexicano y la segunda, la de los bugarrones, al de mayate señalado anteriormente. En $E C V$, entonces, el mundo representado se 'homosexualiza' a través del discurso del narrador, en correspondencia con su propia estética carnavalesca (en la que Bajtín además propone el concepto del "mundo al revés") y las intenciones políticas de Arenas. ${ }^{5}$

El solo ejercicio de homosexualizar toda la isla de Cuba desde el inicio muestra una intención vindicativa que implica, entre otras cosas, una configuración literaria (estética y discursiva) peculiar dentro de la tradición hispanoamericana. "Del bugarrón" (78-82), el primer episodio en prosa, narra el inicio del día de un viejo bugarrón y su travesía en busca de otro hombre que, como él, prefiera el rol activo en el plano sexual, para culminar en el palacio del dictador precisamente en el día de la celebración del carnaval. Por otra parte, "En el gigantesco urinario" (83-86), en el polo opuesto, se aprecia a Tedevoro, una "loca" que intenta acudir al carnaval. Contrasta la visión de este último personaje con la del primero, sobre todo en la esfera política, pues persigue al carnaval en su plano popular, mientras que el viejo bugarrón sólo ha acudido al lugar oficial de la celebración con intenciones diferentes. Semejantes actitudes ante los actos celebratorios marcarán polos opuestos que apoyarán la estructura discursiva. En el fragmento "Del Bugarrón" se lee que:

...el viejo bugarrón descubrió, con pavor, que en el mundo solamente había maricones. Maricones de todos los tipos; algunos disfrazados de bugarrones; otros, absolutamente tapados o tapiñados (éstos eran los peores), casados, con mujeres, queridas, hijos y nietos, pasaban el tiempo singándose entre ellos o, en la mayoría de los casos, sumidos en una renuncia bovina y beatífica, gastaban sus vidas delante del televisor mirándoles los bultos a los negros jugadores de baloncesto. En fin, gastaban sus vidas en una gran mariconería visual (Arenas, 1999: 79).

Toda la novela parte de este supuesto de "homosexualidad universal", pues se invierte la jerarquía social desde el plano sexual, y contribuye en la percepción del discurso oficial como un mundo heteronormativo que a la postre resulta obsoleto y burlado. Es decir, mientras que la generalización de las relaciones homosexuales configura la diégesis, el discurso oficialista revolucionario persiste caricaturizado, pues pocos acatan sus dogmas. Se configura entonces una sociedad compuesta por bugarrones en representación de lo masculino o viril y locas en relación con lo femenino o afeminado.

Recuérdese la estructura del texto: $E C V$ es una novela fragmentaria dividida en múltiples episodios pretendidamente autónomos, precedidos por una pieza teatral, "La fuga de la Avellaneda: obra ligera en un acto (de repudio)" (17-76), que hace evidente alusión al éxodo del Mariel en 1980. Después siguen 114 fragmentos de los cuales treinta son trabalenguas y el resto lo forman episodios que desarrollan la historia. En cada uno de los fragmentos los personajes intentan acudir al carnaval o se mueven en relación con el mismo. Éste, a su vez, pretende celebrarse por los cincuenta años del dictador en el poder, Fifo, clara alusión a Fidel Castro. Se llevan a cabo, en la anécdota, dos celebraciones: la oficial y la popular, que al final terminan por confundirse.

En el texto, la configuración del orbe se da mediante la oposición de lo queer ante lo patriarcal. La feminidad es también parte importante de esta lucha. A ella se acude dada la marginación de lo homosexual hecha por el ámbito oficial, como testimonio de la violencia de género de una sociedad específica. Se intenta, además, mostrar cómo se crea esta polarización de los ámbitos queer y patriarcal, y su enfrentamiento. Este último existe a partir de marcas discursivas que lo vuelven vigente desde el comportamiento de los personajes, que lo reconocen por su hegemonía. Sin embargo, semejante asociación será desplazada por lo

\footnotetext{
${ }^{5}$ Si bien los trabajos de Núñez Noriega pertenecen al campo de la antropología social, es necesario considerar que muchas de las contribuciones generadas en otras áreas han tenido efectos significativos en los estudios literarios, en donde las subjetividades se estudian en sus correspondencias y traslados hacia los universos discursivos propios de la ficción literaria y su relación con la construcción de conciencias en los personajes literarios.
} 
queer, pues en tal desplazamiento la homosexualidad tomará lo femenino como estandarte y se erigirá como una forma de representación que busca su propia dimensión simbólica en su enfrentamiento con lo heteronormativo.

La asunción de esta "conciencia homosexual" propicia una dialéctica en la que son necesarias algunas estrategias para manifestar su deseo por desestabilizar y derrocar el régimen. Ante este panorama, la disidencia sexual desde el margen alimenta una propuesta narrativa con intenciones políticas que intenta situarse en el sitio de poder, visiblemente en pugna.

En lo marginal se aprecia esta situación de caos y desalojo, y se coloca a lo homosexual y la feminidad como estatuto del otro. Además la ordenación simbólica, en el sentido de las referencias explícitas al falo, manifiesta hiperbólicamente su deificación. En este sentido, los aspectos y mecanismos de institución del sujeto homosexual hacen también visible este marco de lo queer, especialmente en el énfasis del protagonista puesto en los primeros fragmentos que narran sus "viajes". Las instituciones que detentan el poder se verán conflictuadas posteriormente por otros intentos de ordenamiento derivados de la configuración de un universo diegético en conflicto.

Lo anterior pudiera comprenderse como un claro intento de subversión y denuncia. En la Cuba revolucionaria, la cuestión del género se entiende al analizar el contexto cubano desde la idea de lo nacional. Inmaculada Álvarez en "El discurso sexual como valor de identidad nacional de lo cubano" (2003) examina la articulación y el avance del discurso sexual en lo que concierne a los mecanismos de control social y géneros sexuales que influyeron en la representación de la identidad cultural en el siglo XX mediante el concepto de "cubanía" como discurso nacional. Álvarez hace un ilustrativo recorrido desde finales del siglo XIX hasta los albores del siglo XXI; sobre cómo en el contexto cultural e histórico de la época surgió la necesidad de erigir los códigos que afianzaran una identidad digna del periodo independentista latinoamericano, en donde se establecieron intenciones políticas que coincidieron "con la formación de los discursos nacionalistas" $(15-16)^{6}$ :

Mediante esta foucaldiana relación de poder individuo-Estado se pretendía [...] la salvaguarda de la familia como unidad social básica garante de la reproducción. Con ello, la heterosexualidad se consideró el único modelo sexual aceptable y "natural”, considerándose como rechazable socialmente cualquier otra orientación sexual diferente (Álvarez: 14).

Esta autora encuentra que "La homosexualidad, por ejemplo, era considerada como una amenaza para «lo cubano» ya dentro de los primeros discursos nacionalistas de Martí" (15). En este sentido, José Martí promovió un modelo de virilidad retomado luego por la revolución cubana como estereotipo de masculinidad. Además, Álvarez explica que lo nacional se define a partir de la diferencia y el establecimiento de un territorio común con mitos propios que le permiten explicar el desarrollo de la identidad sexual en Cuba, que a su vez se "transforma" en "valor de identidad nacional" (17). También destaca cómo al identificar la cobardía con lo homosexual, esta se aparta del imaginario surgido en torno al "valiente héroe militar" (18) enaltecido en el pensamiento de José Martí, convirtiendo este proceso en "símbolo de formación de lo nacional cubano" (19), y contrapuesto a la figura de Julián del Casal". Martí además contrapone el modelo ideal masculino del hombre cubano frente al hombre afeminado ${ }^{8}$.

El posterior desarrollo de la isla, hasta la revolución de 1958, se incentiva la imagen de Cuba como un paraíso:

La elaboración simbólica de Cuba y La Habana como lugares de desinhibición sexual, mantenida hasta hoy, fue construyéndose especialmente durante las décadas de los años 30, 40 y 50 a través del imaginario definido por el cine y la música, que estaban determinados por el mercado turístico norteamericano, principalmente (22).

\footnotetext{
${ }^{6}$ Sobre este asunto Álvarez añade que: "Los discursos sobre nacionalismo y control sexual coinciden en un punto común: ambos construyen su identidad con el referente de su diferencia ante el Otro" (16). Semejante conflicto también se encuentra presente en la novela que aquí se analiza.

${ }^{7}$ Sobre este otro aspecto, la autora precisa que: "En 1892 Manuel Cruz escribe Cromitos Cubanos, un manual sobre personalidades cubanas desde 1860 hasta 1898. En él se hace un expreso rechazo a la figura del poeta modernista Julián del Casal, considerado como «hombre afeminado y sin hombría» que le apartaría del ideal masculino nacional" (19).

${ }^{8}$ Por otra parte, en relación con la construcción de las mujeres como personajes literarios, Álvarez menciona novelas que construyen la figura femenina como voluptuosa y apasionada, tal es el caso Las Impuras, situación que persiste en el imaginario de la isla hasta la llegada de la revolución. Esta concepción de lo femenino es retomada por Arenas en su texto.
} 
La autora sustenta su tesis con diferentes datos que brindan una lectura acerca de cómo se percibía la sexualidad en la isla ${ }^{9}$ hasta la llegada de Fidel Castro, donde expresa que:

...la Revolución unió el proyecto político y económico al de regeneración social de la Isla, y el régimen entendió tanto a la homosexualidad como a la prostitución como una consecuencia de la "degeneración de la burguesía fascista de Batista", en palabras de Castro. Comenzó entonces una represión política y social: en 1960 se clausura la revista Ciclón, cuyo editor, José Rodríguez Feo, era conocido por su homosexualidad, y en 1962 el escritor Virgilio Piñera es arrestado por su apariencia de "hombre afeminado" y su vida "escandalosa" [...] En 1965 se crean las UMAP (unidades militares de ayuda a la producción), campos de trabajo agrícola donde homosexuales e intelectuales opuestos al régimen eran condenados y recluidos [...] la Cuba de la Revolución recordaba de nuevo el ideal de hombre viril militar de los primeros años de independencia del país, pero ahora reconvirtiéndose como icono del buen cubano revolucionario. [...] De esta forma la homofobia pasó no solo a institucionalizarse, sino a convertirse en valor nacional (27).

Es hasta la década de los noventa cuando, sin el apoyo de la Unión Soviética, Cuba debe regresar a las representaciones que se habían hecho sobre la propia identidad antes de la revolución.

El análisis de Inmaculada Álvarez resulta pertinente porque muestra, a partir de manifestaciones artísticas representativas de la tradición insular, los imaginarios sociales históricos, sus cambios y las representaciones tanto de lo femenino como de lo masculino. Reinaldo Arenas, quien desarrolló su producción artística dentro de este contexto, resulta decididamente un elemento importante, junto a Sarduy, Piñera y Lezama Lima, para comprender la magnitud de sus denuncias, implícitas y explícitas, y su posterior apertura desde el margen.

\section{Sobre la institución de un sujeto marginal homosexual}

El poder patriarcal es entendido como aquel que instaura al hombre como sujeto universal, desde su condición como masculino, y el resto es interpretado como lo otro (Wittig, El pensamiento heterosexual, 1992). Aunque la estructura del texto es aparentemente caótica, ECV reproduce representaciones sociales del homosexual desde retratos íntimamente relacionados con el núcleo familiar. En "Viaje a Holguín" (114-119), "Antes de emprender un largo viaje" (122-125) y "Viaje en tren" (127-135) es evidente la subyugación de lo femenino en la perspectiva de la madre y el hijo. Estos fragmentos, cuyos títulos presentan la secuencia que narra la visita del protagonista a su madre, ofrecen una génesis y explicación del tratamiento del género sexual sobre la concepción de lo femenino convencional limitado dentro del sistema patriarcal.

El narrador protagonista relata el universo creado desde una alteridad que irá desplazando y destronando la categoría de sujeto. O sea, lo patriarcal es lo arcaico y lo nuevo que está en efervescencia y acercándose al centro es la forma, feminizada, de entender el deseo homosexual. Esto se visibiliza en "Viaje a Holguín", donde se cuenta la visita a su madre en la ciudad natal. Al llegar le encuentra barriendo, acto del que posteriormente hace una interpretación para después pasar a la interacción desde donde se observa al personaje en su faceta de hijo, Gabriel; como homosexual, se presenta como La Tétrica Mofeta; y el escritor se asume como Reinaldo, en clara consonancia con el autor de la novela y desde donde se puede pensar en la posibilidad de un sentimiento autobiográfico:

Y el hijo [...] sentía unos enormes deseos de llegar hasta la madre y abrazarla suplicándole que no pusiera esa cara de pena [...] que si se había casado y hasta había tenido un hijo era para que ella pudiera decírselo a sus amigas y sin duda a la escoba, acallando así cualquier sospecha sobre la vida sexual de él, su hijo [...] Y sobre todo, mira, mira, no me he traicionado a mí mismo. No soy una persona, sino dos y tres a la vez. Para ti sigo siendo Gabriel, para aquellos que leen lo que escribo y que casi nunca puedo publicar soy Reinaldo, con el

\footnotetext{
${ }^{9}$ Los siguientes son los datos que sustentan la hipótesis de esta investigadora: 1) “«Ley Seca» (Volstead Act) de 1919, que prohibía la venta y consumo público de alcohol en Estados Unidos" (22); 2) la isla como "un «otro exótico» [para Estados Unidos] a donde escapar de la realidad cotidiana [...] el turismo a Cuba se disparó: de 33000 turistas en 1914, se pasó a 200000 en 1945; así como también el número de cabarets y prostíbulos registrados oficialmente: 4000 en 1912 y más de 13000 en 1950." (23); y 3) el "símbolo diferenciador de esa cubanía [...fue el] Negrismo, del que participaron escritores como Nicolás Guillén, Emilio Ballagas, Lydia Cabrera o Alejo Carpentier". Finalmente sostiene que “el negrismo sigue manteniendo la elaboración en el imaginario de la sensualidad voluptuosa de la mulata, aunque ahora entendida como símbolo de poder sexual sobre lo blanco. De esta manera, este mito pasa a convertirse también en un valor del nacionalismo cubano" (25).
} 
resto de mis amigos, con los cuales de vez en cuando me escapo para ser yo totalmente soy la Tétrica Mofeta (Arenas, 1999: 115).

Se observa, por medio del estilo indirecto libre, el cambio a un personaje que se configura como central y, al final, en femenino. Se puede distinguir, además, un narrador heterodiegético que intenta aprehender el mundo representado, lo extradiegético, al retratar papeles previamente asignados dentro del discurso oficial, como el caso de la madre, en consonancia con el suyo:

\begin{abstract}
...casarse, olvidarse de sus preferencias sexuales, de su propia vida y pensar en la vida de aquella vieja solitaria, dueña solo de una escoba. Sí, se casó (la madre fue a la boda), tuvo un hijo (la madre fue al bautizo casi clandestino). Gabriel se transformaba en la Tétrica Mofeta, disfraza de hombre y, niño en brazos, la esposa al lado, sentía una llamada más ineludible que todas las otras llamadas. Y comprendía que para él no había otra redención que llegar a acostarse con alguno de aquellos hombres que furtivamente contemplaba. A Reinaldo le fue imposible, aun cuando se refugiase en la literatura, desobedecer aquella llamada más poderosa que cualquier peligro y Gabriel volvió a ser la Tétrica Mofeta (Arenas, 1999: 117).
\end{abstract}

La necesidad de asumirse como sujeto homosexual es evidente; es una cuestión de identidad y libertad, pues se privilegia el sexo como una marca indeleble del cuerpo ligada a un rol determinado por el deseo. También se muestra la preponderancia de la identidad homosexual frente a las otras como una necesidad con intenciones políticas, de representación. La novela contiene extensos apartados en los que se cuentan las vidas de muchos otros personajes homosexuales, como el caso de Tedevoro y Santa Marica. Respecto del protagonista, "Viaje a Holguín" condensa cómo se ve la cuestión de género desde el punto de vista heteronormativo. Aparecen las visiones del género en pugna a partir de la representación de la madre como mujer, en el sentido de categoría de género, además del hijo homosexual en una sociedad específica, la Cuba posrevolucionaria en crisis. Esta relación madre patriarcal-hijo homosexual marginado se tamiza en "Antes de emprender un largo viaje" (122-125), donde se ve más la cuestión homosexualidad-patriarcado. Ambos fragmentos integran una unidad, pues se inician con las mismas primeras tres oraciones. En el barrio "Vista Alegre" se ve barrer a la madre del protagonista, acto del que se hace una interpretación, de donde se sigue lo mencionado acerca del sujeto femenino configurado a desde el sistema patriarcal:

Gabriel dejó de escribir y pensó que aquella escritura tampoco iba a remediar el sufrimiento de su madre. Por el contrario, de leer aquel manuscrito se pondría aún más triste. Durante la noche que pasó en Holguín tuvo mucho cuidado de que la madre no descubriese la novela y la había metido en un falso forro de su mochila. Como todas las cosas auténticas que había hecho en su vida, también esa novela tenía que ocultársela a la madre (Arenas, 1999: 122).

En el ejercicio de la rescritura se aprecia el rol de lo femenino configurado desde las construcciones tradicionales, que en algunos aspectos impide o imposibilita la comunicación con la madre. Esta última es abandonada por el hombre (el padre del narrador) e incapaz de producir o retener uno (el hijo o el padre), se coloca así en el espacio de lo marginal. En el episodio titulado "A la salida del castillo de El Morro" (278285) se narra otro encuentro con la madre, en donde manifiesta su deseo de continuar con el rol materno y llevarse lejos al protagonista una vez que éste ha salido de prisión. En esta parte del texto el narrador protagonista se identifica ya desde su concepción feminizada, como la Tétrica Mofeta. En un enfrentamiento moral con la madre se conecta al episodio con los "viajes". Se expresa aquí conscientemente la asunción de la otredad entendida como objeto, por su condición marginal:

Su madre, llorando, le dijo:

-Vine a buscarte para que te fueras conmigo para Holguín. Tarde o temprano tendrás que hacerlo y cuanto antes mejor. Ésa es la única salida que te queda.

Súbitamente la gran pena que sentía la Tétrica (y Reinaldo y Gabriel) se convirtió en furia; furia contra la vida, contra el castillo de El Morro, contra él mismo, la Tétrica, y contra su propia madre, por lo que, moviéndose hacia ella, le respondió:

-Mamá, después de haber vivido dos años en un castillo, no piense que voy a meterme en un tugurio de Holguín. En cuanto tuve uso de razón, lo primero que quise hacer, (y luego hice) fue irme de aquel pueblo, de aquella casa horrible, de ti misma, y ahora mis planes son irme del país. No quiero vivir mucho tiempo y lo poco que quiero vivir no lo quiero vivir en este país. Así que adiós (Arenas, 1999: 278). 
Llama la atención la ironía "castillo-tugurio" como una forma de constituirse desde estos juegos semánticos sobre el espacio: la prisión-castillo como sitio de lo masculino frente a la casa materna-tugurio carente de ello. El personaje se revela además en su incapacidad para pertenecer a un lugar, pero con la capacidad para intentar generarlo y/o buscarlo en el margen, que se representa posteriormente en el parque Lenin, donde puede existir como persona, aunque sin la calidad de sujeto, porque en la vida clandestina debe relacionarse con el poder: militares, "turistas extranjeros y putas sofisticadas" (279). Esta desproporción inaugura una característica importante de su condición: "la fuga. Siempre la fuga" (281), como si en esta condición se expresara la oportunidad de enunciarse.

En el caso de la madre, es notoria la vergüenza o los sentimientos negativos de los que no puede desprenderse dada su condición femenina en relación con lo patriarcal, especialmente en el episodio "El jardín de las Computadoras" (413-418), donde todo está controlado por máquinas-monstruo. Se aprecia una visión limitada del homosexual desde la madre como representante de la institución familiar. En este episodio se caracteriza a las computadoras como animales, hasta cierto punto grotescos, pues en ellas radica el poder de Fifo, presente a través de informes y denuncias de cualquier tipo. Hacia el final de la novela, la aparición de la madre con la intención de denunciar a su hijo se trivializa, pues ya se han mostrado los fracasos anteriores por corregirlo. La madre entrega un informe sobre Arenas, y la rescritura de su obra, sus manuscritos, con la esperanza de "reeducarlo": "Por último le decía [...] que esperaba que él, Fifo, regenerase a su hijo y lo encarrilase por el buen camino" (415). El discurso maternal se une al oficial, en este punto ya decadente, del trabajo y la producción, y al señalar la marginalidad de la homosexualidad se observa lo obsoleto de esa feminidad convencional y los valores que persigue.

Los homosexuales como personajes marginales en ECV sólo obtienen un lugar dentro de lo oficial siempre y cuando la asunción misma de su condición se lleve a cabo. En la práctica social esta reificación debe darse desde un marco de referencia o instancia que los determine: el margen. Desde ahí, el rol de las mujeres también es asumido en relación directa con lo sexual, como es el caso de Clara Mortera que, pese a su oficio artístico, debe prostituirse para poder subsistir.

La idea de ver en Arenas esta preocupación por la instauración del género se comprende al revisar sus propias circunstancias. Su ingreso de adolescente en el ejercicio revolucionario que da cuenta de su experiencia frente al poder y la figura de la madre como mito fundacional son importantes en la configuración de un protagonista que es esa "sola persona dispersa" (357) presente en la pentagonía y la obra areniana en general.

\section{La ordenación simbólica desde su formulación falogocéntrica}

Lo que interesa en este apartado es observar cómo se representa el falo en el texto dadas las dimensiones simbólicas en juego, para después ver los mecanismos que promueven su desestabilización. La idea de generar una dialéctica con miras a la reordenación del espacio simbólico, que ya ha sido señalada por la teoría de género como poco viable ${ }^{10}$, en el texto funciona como un conjunto de aspectos dirigidos a problematizar el orden establecido; en este sentido, su revisión se vuelve necesaria para los propósitos estético-literarios que el texto propone. En la novela aparecen escenas y situaciones en las que se reproduce el marco heterosexual de la producción del placer y distribución del deseo (homo)sexual, en las que se aprecia la reproducción en serie de la cópula heterosexual; sin embargo, a la par se despliegan formas alternativas desde los cuerpos más diversos. El falo se representa desde ese carácter universal requerido al relacionarlo con la hipérbole; no obstante, la situación política de su representación en el texto logra el cometido de visibilizar, en el planteamiento de la diversidad sexual, una vía alterna que deslegitima el orden patriarcal.

En ECV el hombre se reconoce como universal porque es el portador del falo. La peculiaridad de esto es que dicho estatuto es otorgado desde la visión homosexual tanto del narrador como de otros personajes. Por ejemplo, en "Las tortiguaguas" el narrador dice que estos últimos están "persiguiendo como siempre el sueño dorado: un hombre" (105). En esta parte, al hombre se le representa como un policía, autoridad a la que se le

\footnotetext{
${ }^{10}$ En cuanto a los planteamientos de Monique Wittig, Judith Butler opina que "la disyunción radical propuesta por Wittig entre heterosexualidad y homosexualidad no es cierta, que hay estructuras de homosexualidad psíquica en las relaciones heterosexuales y estructuras de heterosexualidad psíquica en las relaciones y la sexualidad gay y lésbica" y añade que "hay otros centros de poder/discurso que elaboran y estructuran tanto la sexualidad gay como la hetero; la heterosexualidad no es la única expresión obligatoria de poder que inspira a la sexualidad” (Butler, 2002: 242).
} 
adjudican atributos como "rotundo dios malvado", "bello ejemplar represivo", "policía-primor", "bello policía" (111). En cambio, al protagonista, quien delinque desde su sola presencia y cuya incursión es relatada de manera despectiva por el grupo de locas previamente desalojadas de la playa, lo describen afirmando que vieron "la figura de un pájaro flaco y desgarbado salir del pinar descalzo [...] Se trataba de la Tétrica Mofeta" (106). A esta caracterización polarizada de los personajes homosexuales como locas/pájaros, frente a la idea convencional del hombre como heterosexualmente "flexible" o bugarrones, se adhiere otra particularidad: también la edad suele ser determinante en dichas relaciones, pues se identifica al hombre joven con la vida-lozanía, y al narrador y protagonista, la loca, como mayor y cercano a la muerte. Pese a esto, el deseo por el falo como valor de cambio resulta una especie de puente que vincula a un agente con el otro.

En "Viaje en tren" la interrupción del militar cae en esta polarización antes mencionada:

\begin{abstract}
$\mathrm{Y}$ ambas locas, anonadadas por tanto calor, tanta fealdad y tanta peste, se arrellanaron en sus molestísimos asientos [...] Ay, querida, pero en ese momento, y ya en el tren bramaba en son de fuga, una especie de luz irrumpió en el vagón. Era como un pez dorado en un mar poblado sólo por tiburones deformes, [...] Era, en fin, carajo, el espléndido recluta a quien la Tétrica le había preguntado la hora y que le dio una patada moral [...] y el macharrán, sin mirar a sitio alguno, como si caminara por el mismísimo pasillo que da al trono, siguió avanzando, localizó finalmente un asiento libre, tiró a un lado su jolongo verde oliva y se despatarró, extendiéndose en el asiento cuan largo e imponente era (Arenas, 1999: 131).
\end{abstract}

Este acto de divinizar a personajes masculinos es recurrente, mientras que el homosexual se ubica desde lo opuesto. El personaje de la Reina de las Arañas, en contraste, se ha descrito antes en el fragmento como "traquimañera, astuta, horrorosa, siempre dando saltos y moviendo pies y manos al mismo tiempo" (129). También la Tétrica Mofeta, al tener éxito su compañero, se piensa como "una loca de desecho, una vieja carenga, un maricón de asilo, y aquél reclutón imponente la había despreciado no porque no le gustaran los pájaros, sino porque no le gustaba un pájaro viejo y decrépito" (133). El falo, como síntoma de realización, se dimensiona como "inestimable tesoro", "gigantesco miembro" de "divinas proporciones" (133), y al exitoso acercamiento sexual de la Reina de las Arañas se considera "triunfo", hasta que el recluta despierta y lo agrede. Estas agresiones de bugarrones hacia locas resultarán iterativas en otras situaciones donde el falo se posiciona como la forma sublime de placer, pues sus son portadores vistos como el sujeto en su sentido universal ${ }^{11}$.

El caso más representativo resulta ser La Llave del Golfo, el amante titular de la Tétrica Mofeta. Si bien el apodo lleva el artículo femenino, resulta ser masculino dado el sentido simbólico y sexual en el rol que se le atribuye. Aunque el género del nombre es femenino, "La llave", como metáfora del falo le masculiniza. Continúan además los atributos con los que se denota la cuestión generacional. Tanto el recluta del ejemplo anterior como la Llave del Golfo tienen el atributo de poseer, tener, el falo, desde su concepción lacaniana, además de estar asociados con la vida y no con la muerte, que corresponde a las locas ancianas.

El episodio "La Llave del Golfo" (233-238) relata la historia de la Tétrica Mofeta y este personaje. La parte donde se explica el origen del nombre revela cierta necesidad de generar una contraparte respecto a la preponderancia del falo: "Al fin había encontrado el dios anhelado, la horma de su zapato, la Llave del Golfo, pues golfo era lo que ella tenía y sólo aquella monumental llave era capaz de ajustarse a tan gigantesca cerradura" (234), en referencia al ano como órgano disponible para el placer sexual. Más adelante, al percatarse de las infidelidades de su amante, la Tétrica Mofeta puede confundir las categorías de clasificación sexual: "estuvo meditando; por último llegó a la conclusión de que quería demasiado a aquél joven para renunciar a él por un problema de faldas. Si le gustaban las mujeres, mejor, se dijo; eso demuestra que es un hombre de verdad" (235), lo que muestra una definición del otro a través del deseo, mientras que el homosexual se asume como en una situación liminar en relación con los géneros, pues no se identifica con las categorías hegemónicas existentes.

\footnotetext{
${ }^{11}$ Otros personajes masculinos importantes a quienes se relaciona desde lo predominante fálico son Tiburón Sangriento y Tatica, el "Ángel Azul de Marianao" (Arenas, 1999: 171). Este último engaña para robarle las aletas a La Tétrica Mofeta, e igualmente golpea, con el mismo objeto que hurta, a Coco Salas. Tatica se revela igualmente desde la idea de lo divino, como "dios" (170), y las formas para referirse a su miembro van en este tenor, como "divino prepucio", "atributos celestiales" y "celestial miembro" (171). Tiburón Sangriento tiene igualmente estas características: se trata de un monstruo "atlético, musculoso, brillante" con "un sexo prominente que usaba de manera sádica" pese a ser una criatura "bella" (138).
} 
Esta importancia del falo como atributo físico y ordenador simbólico tiene una intervención posterior: "La elevación del Santo Clavo" (439-442) relata la peculiar ceremonia carnavalesca donde se hace una felación colectiva a La Llave del Golfo. Parodia de las ceremonias antiguas, este fragmento constituye una muestra de cómo la figura del falo como símbolo deviene en crítica que trastoca incluso esferas como la religiosa o la económica ${ }^{12}$. Al mismo tiempo que desde el nombre del evento se parodia la formulación de los ritos religiosos, católicos en específico ${ }^{13}$, se entiende finalmente la idea de concurso o competencia por los fines económicos que se persiguen, de donaciones monetarias para la manutención del régimen dictatorial. En esta mezcla de lo ritual y lo económico puede verse una parodia de las formas falogocéntricas como instituciones que actúan sobre y en el cuerpo. Desde el plano económico, esta forma de la inserción del falo en la cultura permite que sea reelaborado como un símbolo a merced del poder, comprometiendo así su propio lugar simbólico. Es decir, el falo como producto también debe participar en las dinámicas más avasalladoras de la civilización. En este fragmento, desde el contexto del mundo homosexualizado el placer se superpone y todo el pueblo participa del ritual. El protagonista, celoso, consigue interrumpir el acto al mentir y hacer que los ciudadanos busquen refugio en una embajada. Esta es una de sus estrategias más afortunadas, pues con ello iniciará la construcción del final de la historia.

"La conferencia de Lezama" (287-299) pretende ser un episodio importante. Como personaje, Lezama (en clara alusión a José Lezama Lima) sobrevive a las descripciones satíricas que Arenas dedica a muchos otros autores contemporáneos. Esto gracias a la relación mentor-alumno establecida entre Arenas y la figura del autor de Paradiso ${ }^{14}$. En su discurso, el personaje de Lezama habla de las civilizaciones antiguas como adoradoras del falo: "griegos armoniosos, quienes rendían un tributo tan desmesurado y justo a la verga triunfante que la divinizaron, creando así al dios Príapo" (288), para continuar con el cristianismo: "nos conmueve Cristo porque tiene falo, y su cuerpo, por lo mismo humano, aparece en la cruz desnudo" (288). No obstante, se trata de un ejercicio que promueve la trasgresión y el escándalo. La tesis que presenta Lezama se puede apreciar también como pretexto para ejercer el erotismo y así vincular el sexo con una apreciación y experimentación estética. Como un remedo de artículo académico, el personaje expone varios casos en un intento por proponer una revisión "histórica" del arte florentino. En la explícita descripción del acto sexual (294-298) menciona las obras que fueron creadas bajo el trance sexual de Miguel Ángel con su modelo para el David; o sea, el sexo homosexual funge como pretexto hiperbólico que engendra arte y bienes simbólicos culturales.

Con esta parodia Reinaldo Arenas intenta, a través de arriesgados métodos narrativos, desmitificar el curso del desarrollo del arte renacentista a través de la hipermitificación del falo. Poner en circulación "el apogeo fálico" (294) como un sistema de realidad, o revisión histórica, obedece a fines políticos dentro de la evidente militancia de una voz definida desde los márgenes del discurso y que busca legitimar el placer. Para ello, el uso de Lezama Lima como personaje resulta pertinente pues se trata de una figura reconocida por su estética neobarroca dentro de la tradición literaria cubana: se persigue cierta legibilidad o deferencia para con la tesis expuesta; amén de que su obra, Paradiso, constituye un hito para la literatura cubana al presentar anteriormente protagonistas homosexuales ${ }^{15}$. Arenas intenta, además, enfatizar en una pluralidad y/o

${ }^{12}$ Entendida esta como esfera angular en el desarrollo de la cultura. Muchos de los personajes se ven sometidos a la carencia de poder adquisitivo, como una forma de denuncia y posicionamiento dentro de lo marginal mediante esta visibilidad de la pobreza y carencias económicas. En este artículo se identifica como "lo económico" a esta otra zona marginal tan presente en el texto.

13 "Crucipinguificación" (227-229) es uno de ellos. Se trata de un destronamiento de género porque consiste en el asesinato (con golpes y violencia propios de la estética cómico-grotesca) a partir de la penetración en todo el cuerpo. De nuevo se encuentra este doble elemento placer-muerte que vuelve ambiguo al rito. Y un uso político ambiguo porque se describe como "goce supremo [...] hombres, mujeres y pájaros saltaban enloquecidos queriendo ser seleccionados por Fifo" (227).

${ }^{14}$ Nieves Olcoz en "Delitos y sueños de Reinaldo Arenas" distingue diferentes rasgos de la vida del autor como motivaciones persistentes en su narrativa. Según la autora, Arenas se enuncia desde un "individualismo trágico" que es "heredero de una tradición que no es el de las estéticas oficiales como el realismo mágico o lo real maravilloso, que igualmente buscaban el origen y rescribir los mitos identitarios desde los imaginarios que resonaban ya desde las culturas autóctonas en la historia latinoamericana" (69), y reconoce a Lezama Lima como influencia directa: "Piñera y Lezama engendran una estirpe oscura de esta edad de oro de las letras americanas (la última quizás en la que puedan pensarse en un esfuerzo conjunto), padres imposibles, autores-ombligo, de una perturbada noción de la palabra, en texto que, como los borgeanos, nacen antiguos [...] De aquella empresa narrativa caen epígonos o jóvenes autores - Arenas, Sarduy- que toman la fábula de la representación como motivo autobiográfico" (72).

${ }^{15}$ Emir Rodríguez Monegal, en su revisión del panorama literario hispanoamericano hasta 1971 refería un boom que "no hubiera llegado a ocurrir" sin el régimen cubano. Sobre el proceso político desde la perspectiva editorial revisa las publicaciones de Casa de las Américas a los escritores más importantes y destaca como una excepción la publicación de Paradiso: "En momentos en que el Gobierno cubano había decidido la persecución de los homosexuales [...] Lezama Lima entrega una novela que presenta en forma directa y a la vez metafórica las actividades homosexuales de algunos de sus protagonistas" (652). La admiración de Arenas hacia Lezama, específicamente, está además presente durante todo el texto. El episodio "Muerte de Lezama" (208-209) sirve como un homenaje, en el rito del flagelo con las flores que los personajes realizan. El fragmento relata el momento de catarsis de la Tétrica Mofeta al enterarse de la muerte del poeta: están en "el puente de la represa del parque Lenin": 
especificidad del deseo homosexual para legitimarlo, y así volverlo visible para la condición del arte. Lo propuesto es que el falo responde a estímulos y no importa la marca del cuerpo para el placer.

En conclusión, en las narraciones que se hacen desde estos personajes disidentes y su devoción por el falo podemos hablar de una evidente polarización entre el sujeto y su otro, que puede enunciarse políticamente, muy de la mano con la idea bajtiniana del mundo al revés. Al revertir el esquema heteronormativo, pero manteniendo la estructura de los valores, el otro, en este caso el homosexual, en su intención por crear visibilidad se complejiza y, dada la naturaleza misma del texto, logra una voz con la que puede ser escuchado, convirtiéndose en la instancia de enunciación que logra "objetivar al sujeto", entendido como el hombre masculino. La dialéctica se logra. Así pueden entenderse afirmaciones contradictorias como "Y ella, por ser loca, sólo podía ser al ser ensartada" (184), que aceptan y asumen su propia condición. Otros ejemplos parecen cumplir también con esta función, siempre en constante diálogo con el falo.

\section{La desestabilización como propuesta para un nuevo valor simbólico}

En ECV hay una pugna por la representatividad política en el plano sexual. Por un lado, el sistema patriarcal está presente en la medida en la que es desplazado (y por lo tanto se entiende como oficial y obsoleto) desde el plano marginal, donde la homosexualidad hace uso de las formas de lo femenino como lo otro para instituir una dialéctica en la que al final resulta vencedora. Por otro, lo representado y enunciado desde lo convencionalmente femenino, por ejemplo la idea de la mujer, se concibe también como marginal; es decir, hay una problematización del sujeto que corresponde a los cuerpos y utiliza las categorías de género a partir el lenguaje como una forma de reificación: el homosexual es entendido en la asunción de una situación liminar desde las estrategias que impiden su identificación con lo masculino, por lo que lo femenino actúa como el lugar del lenguaje al que puede asirse.

Si se ha señalado cómo la ordenación falogocéntrica del mundo constituye el marco central desde donde emerge el placer, la propuesta areniana en ECV manifiesta también su contraparte. Se enuncia desde el margen y es en este sitio desde donde la contraposición a la preponderancia del falo se presenta a partir de una utilización que puede trascender este empleo simbólico: el cuerpo femenino y los espacios de receptáculo del falo generan una apuesta por la sexualidad en general, desde cuya otredad o margen surge el complemento (o suplemento) del falo y del sujeto que lo detenta. El otro, como portador del espacio capaz de detentarlo (de ser, en términos lacanianos) se presenta como la vagina, la boca o el ano. Este uso se representa desde la figura de la hipérbole como el hueco ávido que intenta competir con la preponderancia del falo. Esta idea de transgresión en la novela incluso rebasa el campo de lo simbólico. Por ejemplo, el capítulo titulado "El hueco de Clara" (379-394) resulta ilustrativo porque narra cómo Clara Mortera, al dar la noticia de ya no poder ejercer su oficio, de prostitución, sus invitados agujeran la pared del apartamento con el pretexto de crear una ventana para soportar el calor. En lugar de la calle, que era lo que esperaban ver, se topan con el interior de un convento con innumerables riquezas contenidas. Este hallazgo provoca un desplazamiento desde lo económico como método de subsistencia hacia la imagen de la concavidad u oquedad como una alegoría acorde a la estética grotesca.

El episodio cuenta cómo los invitados al apartamento del personaje, incluido el protagonista, descubren en el convento una fuente de riquezas. Al explorarla inicialmente, el narrador cuenta que los personajes "permanecieron por unos instantes en éxtasis, apoyados unos contra otros, respirando aquella paz y aquella grandeza que ya no eran de este mundo. Evidentemente, el hueco de Clara les había deparado no solamente una gran fortuna, sino otro universo" (382), lo que da pie al saqueo de este en una especie de descripción que gracias a la hipérbole y a la idea de hueco como portal para el tráfico de los objetos recuerda la estructura de lo fantástico, además de lo neobarroco. Esta situación se plantea como una usual atmósfera del carnaval:

A pesar de que el tráfico en el hueco de Clara era incesante y éste parecía ya completamente saqueado, a cada rato se encontraban entre los escombros objetos insospechados [...] en una cámara en tinieblas descubrieron un cepo, por lo que a Clara le vino otra vez la idea de castigar a Delfín Proust [...] Ante aquella perspectiva, la Reina de las Arañas [Delfín], salió a escape envuelto en un mantón de holán fino y con su inmensa cabeza cubierta por un sombrero de obispo, tal vez olvidado en aquel lugar desde hacía siglos. Mientras Delfín Proust se escapaba de aquel solar que se había convertido en un hormiguero, subía con parsimonia Oliente

“soltando el gran manojo de flores, Gabriel empezó a aullar sobre la represa. Entonces la Reina de las Arañas comenzó a flagelar a la loca llorona con las largas flores [...] siguió flagelando, ahora con más violencia, el cuerpo y el rostro de la Tétrica Mofeta, que sangraba y gritaba: ¡Lezama! ¡Lezama! Finalmente [...] envuelta en sangre y pétalos de flores se tiró de pie a las aguas de la represa” (209). 
Churre en traje pontifical. Las dos locas se persignaron y cada una continuó su rumbo... (Arenas, 1999: $387-$ 388).

Es evidente, por otra parte, en la narración, que se continúa con la labor crucial de fines económicos y esto se ve en el tráfico a través de este hueco como portal y como corolario metafórico del oficio anterior ejercido por la pintora. Además de las alusiones a los instrumentos sadomasoquistas que sugieren prácticas de este tipo por parte de las religiosas, y por ende un ejercicio hiperbolizado de la sexualidad desde las prácticas patriarcales e incluso disidentes, se ve un intento por cuestionar el voto de castidad de las religiosas.

Una vez saqueado el monasterio, "las barbacoas" (389) son el ejercicio productivo que relata el protagonista como método de subsistencia, al que después sigue la venta de agua y finalmente un locus amoenus que da pie a un invernadero/vivero, para finalizar con el estudio donde la pintora realiza la exposición con la que se cierra el capítulo. Es decir, a nivel estructural hay un uso hiperbólico del lenguaje que busca cierta identificación con lo económico en el desarrollo de la historia, un uso capaz de homologar esta idea de hueco o vacío hiperbolizado al poder falogocéntrico.

En "La condesa de Merlín" (265-275), protagonizado igualmente por el personaje homónimo y en cuyas descripciones se observa un punto de vista colindante con cierta misoginia, se puede observar también esta situación grotesca de cavidad insaciable:

Desde muy niña, con esa ternura que caracteriza a los infantes, María de las Mercedes de Santa Cruz Mopox Jaruco y Montalvo empezó a erotizar a todos los negros esclavos y a obligarlos a que la poseyeran en pleno cañaveral [...] y ay de aquel que se negase a poseer a la voraz niña. La aristócrata infanta intrigaba contra él de tal modo y con tal astucia que los condes de Montalvo y Jaruco terminaban poniéndolo en el cepo y ahorcándolo (Arenas, 1999: 265).

También se menciona su incursión en el "pecado sáfico" (265), así como con "animales de tiro, aves de corral y con instrumentos contundentes" (266). En realidad, en la relación dialéctica del sujeto-falo frente al otro-oquedad se puede sugerir que la hipérbole, al atender a esta forma de lo otro-oquedad, provoca que la figura del falo se desplace y sea insuficiente. Así como la idea de lo masculino puede ser hiperbólica en la penetración constante del orbe, Arenas hace del vacío o la oquedad como forma femenina una condición insaciable, con lo que desestabiliza lo universal simbólico del falo. Incluso se puede pensar en la idea de que el falo es transferible (como lo propone Butler), pues el episodio continúa en este tenor.

En el caso del homosexual, se ubica en el episodio "La Llave del Golfo" al protagonista, la Tétrica Mofeta. El apodo que ha otorgado a su amante, que es el mismo título del capítulo, muestra la vacuidad como una forma de desplazamiento de lo fálico y se desestabiliza la simbología falogocéntrica. Al final del acto sexual se da una importancia altamente significativa a la satisfacción desde el punto de vista del protagonista:

Una felicidad hasta entonces jamás conocida llenaba su piel, volvía sus cabellos sedosos y tupidos, le otorgaba un brillo insólito a sus ojos, inflaba sus arrugas y convertía su rostro en algo fino y terso. Al final había encontrado al dios anhelado, la horma de su zapato, la Llave del Golfo, pues golfo era lo que ella tenía y sólo aquella monumental llave era capaz de ajustarse a tan gigantesca cerradura (Arenas, 1999: 234).

Aunque es evidente que se privilegia lo fálico, el objeto simbólico de lo otro, en este caso la "gigantesca cerradura", se dimensiona también con una fuerza que requiere cierta capacidad análoga para la detentación del poder fálico entendido como significante social. De igual forma, se puede mencionar el caso de Tedevoro, de quien se dice que su "fuego rectal era tan poderoso que aun después de muerta la obligaba a incorporarse, a salir de la tumba o el mar, y lanzarse en persecución de un hombre" (151).

Al proponer que lo fálico en la novela se representa a partir del deseo sexual, esto implica un marco más amplio en la concepción de la sexualidad. La idea patriarcal de la misma se ve desplazada y, por lo tanto, remplazada por un nuevo orden. Este último en ECV muestra que la sexualidad se ejerce hasta desbordarse hacia sí misma y confundirse con la totalidad, dirigida al caos, que es donde la historia se sitúa finalmente.

Al analizar la configuración de la diégesis se ha intentado plantear cómo muchas estructuras que ordenan el mundo están sostenidas por el cuerpo sexuado masculino, y cómo el narrador se vale de múltiples recursos para efectuar su derrocamiento y la destitución del falo como símbolo dominante de la cultura, ya sea hispanoamericana, de tradición católica o judeocristiana ahí representadas. Extensible además a una universalización amparada en la globalidad, dada la confluencia de personajes que acuden al desfile que en la novela se representa. De entre los mecanismos de los que se vale Arenas sobresalen la idea de la esfera económica o productiva, capaz de la desestabilización del falo, y la contraparte de la economía 
falogocéntrica: la feminidad como estandarte de lo queer, que entra como principal elemento político en pugna por el poder (entendido en la novela como la exhibición y el ejercicio del placer en el cuerpo) mediante las representaciones posibles e imposibles del receptor del falo.

El mundo dentro de ECV se configura desde las dimensiones simbólicas que actúan en la cultura y son precisamente desestabilizadas por el margen como espacio social a través de la apropiación de elementos como lo falogocéntrico, su relación con el cuerpo y la idea de lo grotesco. Como se ha visto, el narrador utiliza especialmente las marcas de género para configurar el orbe y emitir su postura política hacia lo sexual. El papel que juega la configuración del narrador ha sido determinante en el entendimiento de un discurso "problematizado", cuyas intenciones políticas son precisamente alcanzar la realidad desde una complejidad que adquiere niveles poco considerados por la crítica literaria tradicional, como por ejemplo la sexualidad del autor de la novela, enunciada también en su propia escritura y sin duda relevante para la comprensión de su propia literatura.

\section{Referencias bibliográficas}

Álvarez, Inmaculada (2003), "El discurso sexual como valor de identidad nacional de lo cubano", Revista de Humanidades. Tecnológico de Monterrey, $\mathrm{n}^{\circ} .14$ (2003), págs. 13-36.

Arenas, Reinaldo (1999). El color del verano o Nuevo "Jardín de las Delicias". Barcelona: Tusquets.

Bajtin, Mijaíl (1993). La cultura popular en la Edad Media y en el Renacimiento. EL contexto de François Rabelais. Trad. de Julio Forcat y César Conroy. México: Alianza.

Butler, Judith (2002). El Género en disputa: el feminismo y la subversión de la identidad. Trad. de Mónica Mansour y Laura Manríquez. México: UNAM-Programa Universitario de Estudios de Género-Paidós.

Correa Mujica, Miguel (1999), "Aproximación crítica a Termina el desfile de Reinaldo Arenas", Espéculo. Revista de estudios literarios, $\mathrm{n}^{\circ} .12$, julio-octubre, 1999. Disponible en: http://www.ucm.es/info/especulo/numero12/arenas.html

Díez Cobo, Rosa María (2007), "El color del verano o Nuevo jardín de las delicias, de Reinaldo Arenas: Humor negro y carnaval narrativo", Espéculo. Revista de estudios literarios, nº 35, marzo-junio, 2007. Disponible en: https://www.ucm.es/info/especulo/numero35/rarenas.html

Nemrava, Daniel (2014), "Encuentro de Dionisio y Dédalo en el mundo híbrido del Color del verano de Reinaldo Arenas", Revista Letral, no 13 (2014), págs. 44-53.

Núñez Noriega, Guillermo (2015). Sexo entre varones. Poder y resistencia en el campo sexual. México: UNAM-CIADCOLSON.

------os (2016). ¿Qué es la diversidad sexual? México: Ariel-CIAD-UNAM.

Olcoz, Nieves (1999), "Delitos y sueños de Reinaldo Arenas", Estudios Públicos, no. 76, 1999. Disponible en: https://www.cepchile.cl/cep/site/artic/20160303/asocfile/20160303184644/rev76_olcoz.pdf

Rodríguez Monegal, Emir (1975), "La nueva novela vista desde Cuba”, Revista Iberoamericana, vol. XLI, nº. 92-93, julio-diciembre 1975, págs. 647-662.

Winks, Christopher (2008), "La isla a la deriva, con sus caras y sus culos. Lo tardío transgresor en El color del verano", en María Teresa Miaja de la Peña (ed.). Del alba al anochecer: la escritura en Reinaldo Arenas. México: UNAMIberoamericana, págs. 103-116.

Wittig, Monique (2006). El pensamiento heterosexual y otros ensayos. Trad. de Javier Sáez y Paco Vidarte. Barcelona: Egales. 